\title{
KEMAMPUAN MENGUBAH TEKS WAWANCARA MENJADI BENTUK NARASI
}

\author{
Reski Amalia Saad ${ }^{1}$, Suhartini Khalik ${ }^{2}$, dan M. Nursin R. Kasau ${ }^{3}$ \\ 1,2,3 Universitas Muhammadiyah Sidenreng Rappang \\ Jl. Angkatan 45 No 1A Lautang Salo Rappang, Pancarijang, Sidenreng Rappang \\ reskiamelia0289@gmail.com
}

\begin{abstract}
Abstrak: Kemampuan Mengubah Teks Wawancara menjadi Bentuk Narasi. Temuan ini bertujuan untuk memperoleh data dan informasi yang lengkap tentang kemampuan mengubah teks wawancara dalam bentuk narasi. Populasi seluruh siswa berjumlah 76 siswa yang terbagi dalam tiga kelas, sedangkan sampel adalah sampel total. Teknik yang digunakan dalam pengumpulan data adalah teknik dokumentasi dan teknik tes. Instrumen yang digunakan berupa teks wawancara yang kemudian siswa ditugaskan untuk mengubah menjadi bentuk naratif. Dari hasil penelitian terlihat bahwa siswa yang memperoleh skor 65 ke atas sebanyak 31 siswa $(40,79 \%)$ dan siswa yang memperoleh skor kurang dari 65 sebanyak 45 siswa $(59,21 \%)$. Berdasarkan standar kualifikasi yang telah ditentukan yaitu siswa yang memperoleh skor 65 keatas minimal 85\%, dapat disimpulkan bahwa siswa belum mampu mengubah teks wawancara menjadi bentuk naratif. karena tidak mencapai standar kualifikasi yang telah ditentukan.
\end{abstract}

Kata Kunci: teks, wawancara, bentuk, narasi.

\begin{abstract}
Ability to Convert Interview Text into Narrative Text. These findings aim to obtain complete data and information about the ability to change the interview text in narrative form. The total student population was 76 students divided into three classes, while the sample was the total sample. The techniques used in data collection are documentation techniques and test techniques. The instrument used was in the form of an interview text which then the students were assigned to convert it into a narrative form. From the research results, it can be seen that students who get a score of 65 and above are 31 students $(40.79 \%)$ and students who get a score of less than 65 are 45 students $(59.21 \%)$. Based on the predetermined qualification standards, namely students who get a score of 65 and above at least $85 \%$, it can be concluded that students have not been able to change the interview text into a narrative form. because it does not reach the predetermined qualification standards.
\end{abstract}

Kata kunci: text, interview, for,. narrative.

Kemampuan adalah kapasitas seseorang untuk melakukan berbagai tugas dalam suatu pekerjaan (Bariah, Effendy, 2017). Kemampuan adalah penilaian terkini tentang apa yang dapat dilakukan seseorang. Mendengarkan merupakan proses mendengarkan simbol lisan dengan penuh perhatian, pengertian, apresiasi, dan interpretasi untuk memperoleh informasi (Nurfidah, 2017), menangkap isi atau pesan, dan memahami makna komunikasi yang telah disampaikan oleh penutur melalui tuturan.
Keterampilan berbahasa mencakup empat aspek penting, yaitu (1) keterampilan menyimak (2) keterampilan berbicara (3) keterampilan membaca, dan (4) keterampilan menulis. Kemampuan berbahasa ini sangat erat kaitannya dengan upaya seseorang untuk memperoleh keterampilan berbahasa yang baik. Berbagai upaya dilakukan untuk membina dan mengembangkan bahasa agar benar-benar memenuhi fungsinya (Muliawati et al., 2018). 
Pendidikan berlangsung dalam suatu proses, proses ini berupa transformasi nilai, pengetahuan, teknologi, dan keterampilan (Puspitasari \& Rustono, 2014). Salah satu cara untuk meningkatkan kemampuan berbahasa Indonesia dengan baik dan benar adalah melalui program pendidikan di sekolah, khususnya mata pelajaran bahasa Indonesia.

Penggunaan aspek kebahasaan dalam proses pembelajaran seringkali berkaitan satu sama lain (Wahana, 2019). Mendengarkan dan membaca sangat erat kaitannya karena keduanya merupakan alat untuk menerima komunikasi atau informasi. Berbicara dan menulis sangat erat kaitannya karena keduanya merupakan cara untuk mengungkapkan makna dan imajinasi (Kertayasa et al., 2019, Syatriana, 2020). Menulis adalah kegiatan mengungkapkan informasi yang diterima dari proses menyimak dan membaca. Jadi semakin banyak seseorang mendengarkan atau membaca semakin banyak yang mereka terima untuk diungkapkan secara tertulis.

Berbicara tentang bahasa Indonesia sebagai alat komunikasi, kita tidak akan lepas dari hakikat komunikasi itu sendiri (Angie, Syambasril, 2017). Bahasa adalah alat komunikasi itu sendiri. Bahasa sebagai alat komunikasi dapat dilihat sebagai saluran yang digunakan oleh penutur untuk menyampaikan informasi atau pesan kepada orang lain. Kemahiran berbahasa dapat ditandai dengan upaya seseorang merangkai kata menjadi kalimat yang pada akhirnya membentuk tulisan atau karangan yang lengkap (Wardana \& Damayani, 2018). Esensi bahasa mencakup konsep bahasa sebagai urutan bunyi yang tidak hanya dapat digambarkan sebagai rangkaian urutan bunyi tetapi juga sebagai gagasan.

Dalam kegiatan menulis ini, seorang penulis harus mahir dalam memanfaatkan grafologi, struktur bahasa, dan kosa kata (Imawati, 2017). Keterampilan menulis digunakan untuk mencatat, mencatat, meyakinkan, melaporkan, menginformasikan, dan mempengaruhi pembaca (Puspitasari \& Rustono, 2014).

Maksud dan tujuan tersebut hanya dapat dicapai dengan baik oleh peserta didik yang dapat menyusun dan merumuskan alur pemikiran dan menuangkannya secara tertulis, lancar, dan komunikatif (Sari, 2017, Sakkir, 2020). Kejelasan ini bergantung pada pemikiran, penggunaan dan pilihan kata, serta struktur kalimat.Wawancara merupakan proses mencari data berupa pendapat/ pandangan hasil observasi seseorang yang akan dijadikan bahan penulisan (Nurfidah, 2017). Kegiatan mengubah teks wawancara ke dalam bentuk karangan naratif memiliki keterkaitan yang sangat erat dengan wawancara karena dalam menulis atau mengutip teks wawancara diketahui bahwa kalimat yang digunakan bersifat langsung dan juga mempunyai bentuk struktur kalimat yang sulit (Agustina, 2019). Memahami, sedangkan dalam Menulis karangan naratif "adalah suatu bentuk wacana yang berupaya menceritakan suatu kejadian atau peristiwa sehingga seolah-olah pembaca melihat atau mengalami sendiri peristiwa tersebut. Oleh karena itu, unsur terpenting dalam suatu narasi adalah unsur aksi atau aksi (Bariah, Effendy, 2017). Berdasarkan pernyataan tersebut dapat disimpulkan bahwa untuk diubah menjadi bentuk karangan naratif "dengan memperhatikan penulisan kalimat langsung dan tidak langsung" (Ramadani, 2019).

\section{METODE}

Temuan ini hanya menggunakan satu variabel atau variabel, yaitu kemampuan menggunakan teks wawancara menjadi karangan naratif (Fahmi, Atmazaki, 2016). Desain yang digunakan adalah deskriptif. Temuan dijelaskan atau diilustrasikan melalui kemampuan menulis esai naratif.

Kemampuan mengubah teks wawancara menjadi karangan naratif adalah kemampuan siswa untuk mengubah teks wawancara menjadi karangan naratif dengan memperhatikan kesesuaian isi, struktur paragraf, struktur kalimat, diksi, dan ejaan (Nugroho, 2017). Dalam temuan ini, kemampuan siswa dalam menulis ulang teks wawancara dalam bentuk dialog yang kemudian diubah menjadi prosa atau esai naratif.

\section{HASIL DAN PEMBAHASAN}

Hasil penelitian ini berupa skor dan nilai hasil belajar siswa dalam mengubah teks wawancara menjadi bentuk narasi. Berikut ini disajikan hasil perolehan tes dalam skor dan nilai.

Tabel 1 Hasil Perolehan Tes

\begin{tabular}{|c|c|c|c|c|c|c|c|c|}
\hline \multirow{2}{*}{ No. } & \multirow{2}{*}{$\begin{array}{c}\text { Kode } \\
\text { Sampel }\end{array}$} & \multicolumn{5}{|c|}{ Unsur yang dinilai } & \multirow{2}{*}{ Skor } & \multirow{2}{*}{$\begin{array}{l}\mathrm{Ni} \\
\text { lai }\end{array}$} \\
\hline & & A & $\mathrm{B}$ & $\mathrm{C}$ & $\mathrm{D}$ & $\mathrm{E}$ & & \\
\hline 1. & 001 & 17 & 11 & 15 & 10 & 9 & 62 & 62 \\
\hline 2. & 002 & 10 & 13 & 12 & 13 & 14 & 62 & 62 \\
\hline 3. & 003 & 15 & 15 & 16 & 11 & 10 & 67 & 77 \\
\hline 4. & 004 & 11 & 10 & 10 & 14 & 11 & 56 & 56 \\
\hline 5. & 005 & 13 & 10 & 9 & 10 & 9 & 51 & 51 \\
\hline 6. & 006 & 10 & 10 & 12 & 10 & 9 & 51 & 51 \\
\hline 7. & 007 & 12 & 10 & 10 & 15 & 10 & 57 & 57 \\
\hline 8. & 008 & 17 & 13 & 13 & 12 & 14 & 69 & 69 \\
\hline 9. & 009 & 19 & 15 & 13 & 18 & 10 & 75 & 75 \\
\hline 10. & 010 & 17 & 10 & 15 & 10 & 9 & 61 & 61 \\
\hline 11. & 011 & 10 & 15 & 15 & 13 & 14 & 67 & 67 \\
\hline 12. & 012 & 15 & 17 & 13 & 13 & 12 & 70 & 70 \\
\hline
\end{tabular}




\begin{tabular}{ccccccccc}
\hline 13. & 013 & 18 & 16 & 12 & 10 & 12 & 68 & 68 \\
\hline 14. & 014 & 15 & 14 & 12 & 10 & 10 & 61 & 61 \\
\hline 15. & 015 & 10 & 15 & 15 & 10 & 10 & 60 & 60 \\
\hline 16. & 016 & 10 & 10 & 12 & 10 & 9 & 51 & 51 \\
\hline 17. & 017 & 12 & 10 & 10 & 13 & 10 & 55 & 55 \\
\hline 18. & 018 & 15 & 15 & 13 & 12 & 10 & 65 & 65 \\
\hline 19. & 019 & 17 & 18 & 15 & 15 & 12 & 77 & 77 \\
\hline 20. & 020 & 15 & 13 & 12 & 10 & 12 & 62 & 62 \\
\hline 21. & 021 & 15 & 15 & 13 & 13 & 13 & 69 & 69 \\
\hline 22. & 022 & 15 & 15 & 13 & 13 & 13 & 69 & 69 \\
\hline
\end{tabular}

Sumber data: hasil tes

Keterangan:
A : Kesesuaian isi dengan bentuk
B : Struktur kalimat
C : Diksi
D : Susunan paragraf
E : Ejaan

Diilustrasikan bahwa tidak ada satu pun siswa yang memperoleh nilai 100. Nilai tertinggi yang diperoleh siswa adalah 77 , sedangkan nilai terendah adalah 46. Berdasarkan analisis data dengan nilai perolehan berikut.

Tabel 2 Nilai, Frekuensi, dan Persentase

\begin{tabular}{cccc}
\hline $\begin{array}{c}\text { No. } \\
\text { Urut }\end{array}$ & Nilai & Frekuensi & Persentase (\%) \\
\hline 1. & 46 & 1 & 1,31 \\
\hline 2. & 49 & 5 & 6,57 \\
\hline 3. & 50 & 3 & 3,94 \\
\hline 4. & 51 & 4 & 5,26 \\
\hline 5. & 52 & 4 & 5,26 \\
\hline 6. & 55 & 1 & 1,31 \\
\hline 7. & 56 & 1 & 1,31 \\
\hline 8. & 57 & 3 & 3,94 \\
\hline 9. & 58 & 1 & 1,31 \\
\hline 10. & 59 & 3 & 3,94 \\
\hline 11. & 60 & 4 & 5,26 \\
\hline 12. & 61 & 5 & 6,57 \\
\hline 13. & 62 & 4 & 5,26 \\
\hline 14. & 63 & 6 & 7,89 \\
\hline 15. & 65 & 4 & 5,26 \\
\hline 16. & 66 & 1 & 1,31 \\
\hline 17. & 67 & 5 & 6,57 \\
\hline 18. & 68 & 4 & 5,26 \\
\hline 19. & 69 & 3 & 3,94 \\
\hline 20. & 70 & 3 & 3,94 \\
\hline 21. & 73 & 2 & 2,63 \\
\hline 22. & 74 & 1 & 1,31 \\
\hline 23. & 75 & 1 & 1,31 \\
\hline 24. & 77 & 1 & 1,31 \\
\hline 25. & 83 & 2 & 2,63 \\
\hline 26. & 84 & 4 & 5,26 \\
\hline & Jumlah & $\mathbf{7 6}$ & $\mathbf{1 0 0}$ \\
\hline Sum. & 1064 & \\
\hline
\end{tabular}

Sumber: diolah dari tabel 1

Data tersebut menggambarkan bahwa jumlah siswa sampel tidak ada siswa yang mendapat nilai 100 . Selanjutnya 4 siswa atau $5,26 \%$ yang memperoleh nilai 84 sebanyak 2 siswa atau $2,63 \%$ yang memperoleh 77 sebanyak 1 siswa atau $1,31 \%$ yang memperoleh nilai 75 adalah 1 siswa atau 1,31\% yang memperoleh 74 sebanyak 1 siswa atau $1,31 \%$ yang memperoleh 73 sebanyak 2 siswa atau $2,63 \%$ yang memperoleh 70 sebanyak 3 siswa atau 3,94\% Yang memperoleh nilai 69 sebanyak 3 siswa atau $3,94 \%$ yang memperoleh nilai 68 sebanyak 4 siswa atau 5,26\% yang memperoleh nilai 67 sebanyak 5 siswa atau $6,57 \%$ yang memperoleh nilai 66 sebanyak 1 siswa. Siswa atau $1,31 \%$ yang memperoleh nilai 65 sebanyak 4 siswa atau $5,26 \%$ yang memperoleh nilai 63 sebanyak 6 siswa atau $7,89 \%$ yang memperoleh nilai 62 sebanyak 4 siswa atau 5,26\% yang memperoleh nilai dari 61 adalah 5 siswa atau 6,57\%, 4 siswa yang memperoleh nilai 60 atau 5,26\% yang memperoleh nilai 59 s Ada 3 siswa atau 3,94\% yang mendapat nilai 58 sebanyak 1 siswa atau $1,31 \%$, yang mendapat nilai 57 sebanyak 3 siswa atau 3,94\%, w ho mendapat skor 56 sebanyak 1 siswa atau $1,31 \%$ yang memperoleh nilai 55 adalah 1 siswa atau $1,31 \%$ yang mendapatkan 52 sebanyak 4 siswa atau 5,26\% yang mendapatkan 51 sebanyak 4 siswa atau 5,26 \% yang mendapatkan 50 sebanyak 3 siswa atau $3,94 \%, 5$ siswa yang memperoleh nilai 49 atau $6,57 \%$, dan 1 siswa atau $1,31 \%$ yang memperoleh nilai 46 .

Untuk mengetahui frekuensi dan persentase kemampuan mengubah teks wawancara menjadi bentuk naratif pada siswa kelas VIII SMP Muhammadiyah Pangsid digunakan rumus persentase dan hasil.

Tabel 2 Klasifikasi Nilai, Frekuensi, dan Persentase Nilai

\begin{tabular}{cccc}
\hline No. & Nilai & Frekuensi & Persentase \\
\hline 1 & 65 ke atas & 31 & $40,79 \%$ \\
\hline 2 & Kurang dari 65 & 45 & $59,21 \%$ \\
\hline & Jumlah & $\mathbf{7 6}$ & $\mathbf{1 0 0 \%}$
\end{tabular}

Sumber: diolah dari tabel 1

Berdasarkan frekuensi dan persentase di atas tergambar bahwa siswa yang 
memperoleh skor 65 ke atas sebanyak 31 siswa atau $40,79 \%$, dan siswa yang memperoleh skor kurang dari 65 sebanyak 45 siswa atau $59,21 \%$. Berdasarkan penelitian yang telah dilakukan terbukti bahwa siswa kelas VIII SMP Muhammadiyah Pangsid belum mampu mengubah teks wawancara menjadi bentuk naratif karena belum memenuhi kriteria yang ditentukan yaitu ketuntasan belajar siswa (sampel). Secara keseluruhan minimal $85 \%$ dari total siswa (sampel) yang mendapatkan skor 65 ke atas.

Hal ini membuktikan bahwa siswa belum memenuhi kriteria penilaian yang ditetapkan dalam ketuntasan pembelajaran yang ditetapkan dalam KTSP yaitu minimal $85 \%$ ke atas dengan skor terendah skor penilaian 10100. Dengan demikian dapat disimpulkan bahwa siswa belum mampu mengonversi teks wawancara ke dalam bentuk naratif.

\section{Penutup}

Berdasarkan temuan tersebut, dapat diambil kesimpulan sebagai berikut.

Berdasarkan tes yang dilakukan ditemukan bahwa dari 76 siswa, 31 siswa $(40,79 \%)$

\section{Daftar Pustaka}

Agustina, A. (2019). Efektivitas Model Pembelajaran Langsung Pada Pembelajaran Mengubah Teks Wawancara Menjadi Karangan Narasi Siswa Kelas Vii Smp Negeri 23 Oku. LENTERA: Jurnal Ilmiah Kependidikan, 12(1), $1-8$. http://dx.doi.org/10.1016/j.respol.2011. 09.003\%0Ahttps://doi.org/10.1016/j.wo rlddev.2020.104995\%0Ahttp://dx.doi.or g/10.1016/j.worlddev.2009.12.011\%0A http://publicaciones.eafit.edu.co/index.p hp/ecos-

economia/article/view/1969/1978\%0Ah ttps://doi.org/10.1016/j.euroe

Atmowardoyo, H., Weda, S., \& Sakkir, G. (2020). Information Technology used by Millennial Good English Language Learners in an Indonesian University to Improve their English Skills. Solid State Technology, 63(5), 9532-9547.

Eni Imawati. (2017). Pengaruh Pembelajaran mendapat nilai di atas 65 dan 45 siswa $(59,21 \%)$ mendapat nilai kurang dari 65 .). Dari hasil pengolahan data tersebut dapat disimpulkan bahwa siswa belum mampu mengubah teks wawancara menjadi bentuk naratif.

Berdasarkan apa yang telah dilakukan, ada beberapa saran antara lain mengingat pentingnya mengubah teks wawancara menjadi bentuk naratif, maka disarankan bagi para guru khususnya guru bahasa Indonesia untuk selalu memotivasi dan memberikan semangat dalam mengubah teks wawancara ke dalam bentuk naratif. Segala bentuk kesalahan yang dilakukan siswa saat menulis harus diperhatikan agar tidak terulang kembali. Diharapkan siswa dalam menulis selalu memperhatikan penggunaan kaidah tata bahasa, bahasa Indonesia, dan ejaan yang disempurnakan. Diharapkan guru bahasa Indonesia lebih memperhatikan kreativitas anak khususnya dalam hal menulis karangan, karena ini merupakan salah satu aspek yang sangat perlu dikuasai dalam pembelajaran bahasa Indonesia.

Berbasis Teks Terhadap Kemampuan Menulis Teks Deskriptif Oleh. Jurnal Literasi, 1 (April), 53-63.

Kasmawati, K., \& Sakkir, G. (2020). IMPROVING STUDENTS READING COMPREHENSION THROUGH "SURVEY, QUESTION, READING, RECITE, REVIEW (SQ3R)" STRATEGY. Interference: Journal of Language, Literature, and Linguistics, 1(2), 92-99.

Kertayasa, I. W., Suandi, I. N., \& Utama, I. D. G. B. (2019). Pembelajaran Menulis Puisi Berdasarkan Pendekatan Kontekstual Pada Siswa Kelas X Mia 2 Sma N 1 Sukasada. Jurnal Pendidikan Bahasa Dan Sastra Indonesia Undiksha, $8 \quad$ (2), 248-259. https://doi.org/10.23887/jjpbs.v8i2.206 18

Lovera Bani Angie, Syambasril, D. R. (2017). Peningkatan kemampuan menulis teks 
prosedur menggunakan teknik $3 \mathrm{~m}$ pada siswa smpn 3 sungai betung. Bahasa, 6 (2), 1-14.

Muhibul Fahmi, Atmazaki, N. A. M. (2016). Peningkatan Keterampilan Menulis Narasi Melalui Model Pembelajaran Langsung Siswa Kelas Vii Smp 26 Sarolangun. Rom J Morphol Embryol, 46(2), (Neurofibroma, schwannoma or a hybrid tumor of the peripheral nerve sheath), 7.

Muliawati, H., Nurzaman, B., \& Oktaviani, N. (2018). Improve Writing Skill Description Text (Meningkatkan Keterampilan Menulis Teks Deskripsi). Indonesian Language Education and Literature, $3 \quad$ (2), 157. https://doi.org/10.24235/ileal.v3i2.1844

Nugroho, A. (2017). Analisis Hasil Kegiatan Interview Mahasiswa Semester Ii/A Program Studi Bahasa Dan Sastra Indonesia Stkip-Pgri Lubuklinggau Tahun Akademik 2015-2016. Jurnal Kajian Bahasa, Sastra Dan Pengajaran (KIBASP), 1 (1), 2597-5218.

Nurfidah. (2017). Analisis kemampuan mengubah teks wawancara menjadi karangan narasi pada siswa kelas vii smp negeri 11 mataram tahun pelajaran 2016/2017. Pendidikan Mandala, 2 (2), 189-193.

Puspitasari, E. H., \& Rustono, H. B. (2014). Peningkatan Keterampilan Menulis Kembali Dengan Bahasa Sendiri Melalui Media Film Dongeng. Jurnal Pendidikan Bahasa Dan Sastra Indonesia, 3 (1), 1-8.

Rahman, H., Sakkir, G., \& Khalik, S. (2020). Audio-Lingual Method to Improve Students's Speaking Skill at Smp Negeri 1 Baranti. La Ogi: English Language Journal, 6(1), 15-21.

Ramadani, S. F. (2019). Kemahiran Mengubah Teks Wawancara Menjadi Karangan Narasi Siswa Kelas Vii Sekolah Menengah Pertama Maitreyawira Tahun Pelajaran 2013/2014. Kemampuan Koneksi Matematis (Tinjauan Terhadap Pendekatan Pembelajaran Savi), 53 (9),
1689-1699.

Sakkir, G. (2018). Pengembangan modul pengajaran menulis berbasis Facebook (Doctoral dissertation, Pascasarjana).

Sakkir, G. (2020). The Effectiveness of Pictures In Enhance Writing Skill of Senior High School Students. Interference: Journal of Language, Literature, and Linguistics, 1(1).

Sakkir, G., Dollah, S., \& Ahmad, J. (2020). Students' Perceptions toward Using YouTube in EFL Classrooms. Journal of Applied Science, Engineering, Technology, and Education, 2(1), 1-10.

Sakkir, G., Dollah, S., \& Ahmad, J. (2020). Favorite E-Learning Media in Pandemic Covid-19 Era. Jurnal Studi Guru dan Pembelajaran, 3(3), 480-485.

Sari, K. (2017). Hubungan antara keterampilan menyimak wawancara dan keterampilan menulis hasil wawancara kelas viii sekolah menengah pertama negeri 10 tanjungpinang. E-Journal, 53 (9), 1689-1699.

Syatriana, E., \& Sakkir, G. (2020). Implementing Learning Model Based on Interactive Learning Community for EFL Students of Muhammadiyah University. ELT Worldwide: Journal of English Language Teaching, 7(1), 2430.

Titik Bariah, Chairil Effendy, S. S. (2017). Peningkatan Kemampuan Mengubah Teks Wawancara Menjadi Narasi dengan menggunakan metode ThinkPair-Share. BAHTERA: Jurnal Pendidikan Bahasa Dan Sastra, 3 (1), 113.

Wahana, R. (2019). Penerapan Model Pembelajaran Creative Problem Solving (CPS) untuk Meningkatkan Kemampuan High Order Thinking Skills (HOTS) dalam Pembelajaran Bahasa Indonesia pada Kompetensi Teks Deskripsi Kelas VII. Prosiding Seminar Nasional Bulan Bahasa (Semiba), 298305.

https://ejournal.unib.ac.id/index.php/se miba

Wardana, M. Y. S., \& Damayani, A. T. 
(2018). Persepsi Pelajar Terhadap Pembelajaran Di Sekolah Dasar. Mosharafa: Jurnal Pendidikan
Matematika, 6 (3), 451-462. https://doi.org/10.31980/mosharafa.v6i3 .333 